\title{
Do we need more than just powerful blood pressure reductions? New paradigms in end-organ protection
}

This article was published in the following Dove Press journal:

Vascular Health and Risk Management

18 June 2010

Number of times this article has been viewed

\author{
Domenico Galzerano' \\ Cristina Capogrosso' \\ Sara Di Michele ${ }^{2}$ \\ Emanuele Bobbio ${ }^{3}$ \\ Paola Paparello' \\ Carlo Gaudio 2 \\ 'Department of Cardiology, San \\ Gennaro Hospital, Naples, Italy; \\ ${ }^{2}$ Department of Heart and Great \\ Vessels, A. Reale, La Sapienza \\ University, Rome, Italy; ${ }^{3}$ Department \\ of Cardiovascular Sciences, Federico II \\ University, Naples, Italy
}

\begin{abstract}
Antihypertensive therapy can lower the risk of cardiovascular morbidity and mortality. Yet, partly because of inadequate dosing, wrong pharmacological choices, and poor patient adherence, hypertension control remains suboptimal in the majority of hypertensive patients. Achieving greater blood pressure control requires a multifaceted approach that raises awareness of hypertension, uses effective therapies, and improves adherence. Particular classes of antihypertensive therapy have beneficial actions beyond blood pressure and studies have evaluated differences in cardiovascular protection among classes. The LIFE and HOPE studies showed between-class differences that may be due to effects other than blood pressure-lowering. In the ONTARGET study, telmisartan and ramipril provided similar cardiovascular protection but adherence was higher with telmisartan, which was better tolerated. This difference in compliance is likely to be important for long-term therapy. The selection of an agent for cardiovascular protection should depend on an appreciation of its composite properties, including any beneficial effects on tolerability and increased patient adherence, as these are likely to be advantageous for the long-term management of hypertension. This review examines the evidence that the effects beyond blood pressure provided by some antihypertensive agents can also lower the risk of cardiovascular, cerebrovascular, and renal events in patients with hypertension.
\end{abstract}

Keywords: angiotensin II receptor blocker, cardiovascular continuum, cardiovascular disease, hypertension, renin-angiotensin system, telmisartan

\section{Introduction}

The incidence of cardiovascular, cerebrovascular, and renal events attributable to elevated blood pressure remains high despite the known consequences of uncontrolled hypertension and the impressive body of evidence for risk reduction with therapeutic intervention. As blood pressure is a major modifiable risk factor, efforts should be directed at achieving good blood pressure control at an individual and population level. This review considers the reasons for the suboptimal management of hypertension and approaches to improving management. An agent that provides effective and sustained control of blood pressure must be the central part of any therapeutic approach to reducing the risk of cardiovascular, cerebrovascular, and renal events. Large outcome trials have angiotensin-converting enzyme (ACE) inhibitors and angiotensin II receptor blockers (ARBs) providing end-organ protection in high-risk patients. There are many contributors to cardiovascular risk in addition to hypertension and these trials also implicate blood pressure-independent mechanisms in reducing cardiovascular risk, suggesting that an agent with these ancillary properties will offer enhanced cardiovascular protection. This review explores this topical theme and examines the evidence
Correspondence: Domenico Galzerano Department of Cardiology, San Gennaro Hospital, Naples, Italy

$\mathrm{Tel}+39812545179$

Fax +39812545179

Email domenicogalzerano@libero.it 
that effects beyond blood pressure can also lower the risk of cardiovascular, cerebrovascular, and renal events.

\section{Hypertension as a risk factor for cardiovascular} and cerebrovascular complications

Hypertension is a major risk factor for cardiovascular and cerebrovascular morbidity and mortality. The evidence from epidemiologic studies and clinical trials has led to the consensus that blood pressure needs to be aggressively controlled. Blood pressure targets are generally consistent among the guidelines produced by national and international bodies. ${ }^{1-3}$ In the Seventh Report of the Joint National Committee on Prevention, Detection, Evaluation, and Treatment of High Blood Pressure (JNC 7), a blood pressure target of $<140 / 90 \mathrm{mmHg}$ is recommended for individuals with uncomplicated hypertension (ie, no end-organ damage or clinical cardiovascular disease). ${ }^{1}$ Reflecting higher risk, the targets are lower for those with diabetes $(<130 / 85 \mathrm{mmHg})$ and for patients with renal insufficiency and proteinuria greater than $1 \mathrm{~g}$ per $24 \mathrm{~h}(125 / 75 \mathrm{mmHg})$. As in the JNC 7 guidelines, the blood pressure goal for hypertensive patients with no other cardiovascular disease risk factors is $<140 / 90 \mathrm{mmHg}$ in the American Heart Association (AHA) and the European Society of Hypertension (ESH) and of the European Society of Cardiology (ESC) recommendations., ${ }^{2,3}$ Also, in common with the JNC 7 guidelines, the blood pressure targets are lower in patients with additional risk factors for cardiovascular disease.

Nonpharmacologic interventions (eg, body weight reduction, exercise, salt restriction, and alcohol intake reduction) yield heterogeneous results and not all may give clinically significant reductions. The most effective approach appears to be weight loss, which may lower systolic blood pressure by $3-5 \mathrm{mmHg} .{ }^{4,5}$ Educational measures, such as sessions

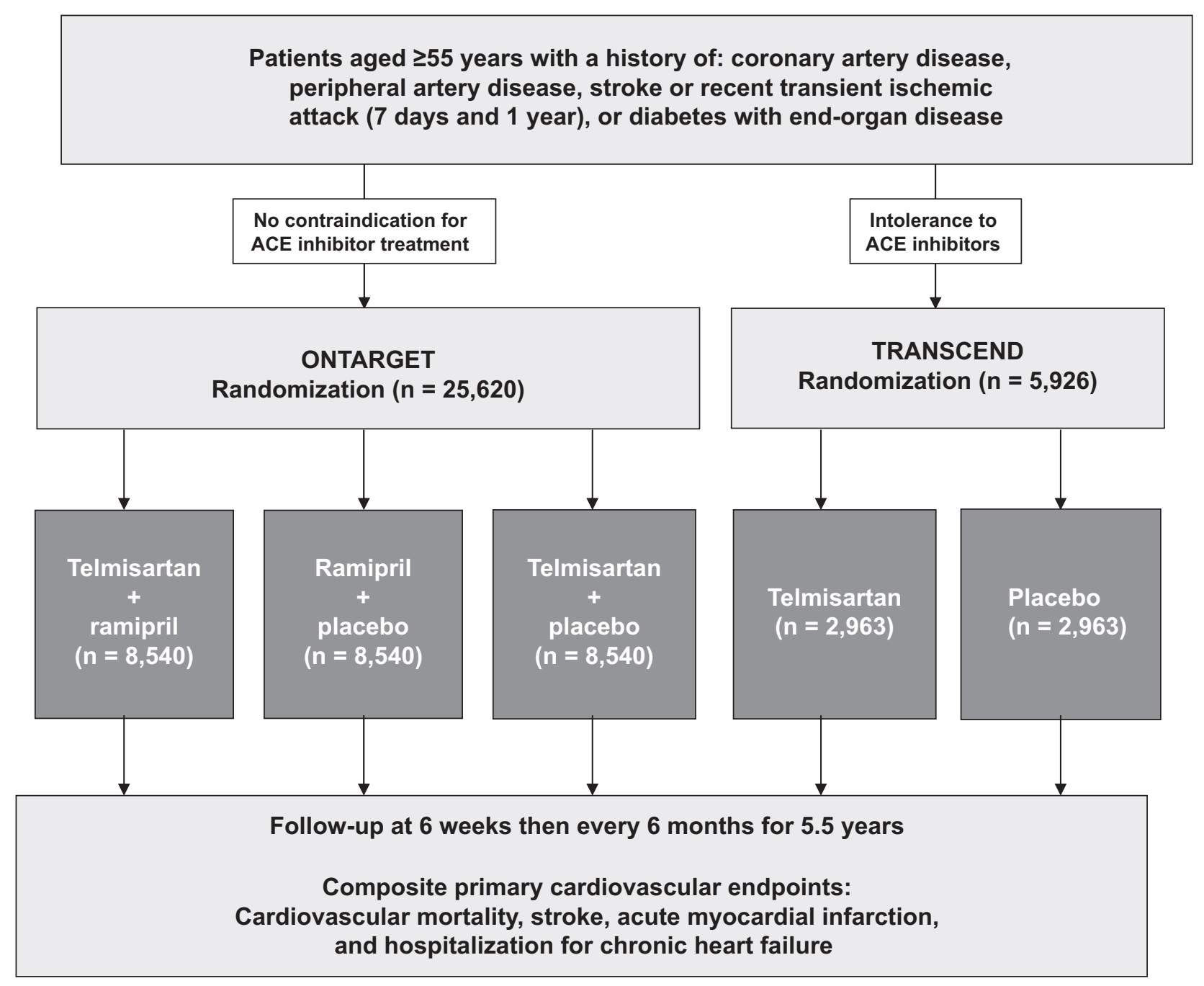

Figure I Design of ONTARGETTM Trial Program. 
with health care professionals or provision of materials, are unlikely to lead to clinically significant reductions in blood pressure. ${ }^{6}$ Thus, alongside lifestyle interventions, antihypertensive medication is generally required to achieve blood pressure goals. Potent and sustained reductions in blood pressure, such as those provided by ARBs and ACE inhibitors, are a requirement of antihypertensive therapy. However, there can be differences in efficacy between classes and even within a class. The differences within a class may reflect important attributes such as half-life, with a longer half-life providing a longer duration of antihypertensive effect. Therefore, it is important to consider each agent individually, to compare the blood pressure-lowering effects of different agents at effective therapeutic doses, and to distinguish between studies that have done so and those that have not. ${ }^{7,8}$

\section{Suboptimal management of hypertension}

Despite awareness of the consequences of uncontrolled hypertension and the impressive body of evidence that blood pressure control significantly reduces the risk of cardiovascular, cerebrovascular, and renal events, the management of hypertension remains suboptimal. In an analysis of the US National Health and Nutrition Examination Survey (NHANES) in 1999-2000, hypertension, defined as blood pressure $>140 / 90 \mathrm{mmHg}$, was present in $28.7 \%$ of the population. ${ }^{9}$ Of those with hypertension, $68.9 \%$ were aware of their diagnosis but only $58.4 \%$ were treated, and control of blood pressure (ie, $<140 / 90 \mathrm{mmHg}$ ) was achieved in only $53.1 \%$. This undertreatment is apparent worldwide. In Canada, the prevalence of hypertension (blood pressure $>140 / 90 \mathrm{mmHg}$ for general population; $>130 / 80 \mathrm{mmHg}$ for patients with type 2 diabetes; $>160 \mathrm{mmHg}$ for isolated systolic hypertension) in a large primary care database was $17.3 \% .{ }^{10}$ Most patients $(68.6 \%)$ had untreated hypertension; only $15.8 \%$ had treated and controlled blood pressure. Undertreatment of hypertensive individuals has also been reported in Italy, ${ }^{11,12}$ the UK, ${ }^{13}$ The Netherlands, ${ }^{14}$ Germany, ${ }^{15}$ and Belgium. ${ }^{16}$

\section{Approaches to improving the management of hypertension}

Among the reasons why hypertension may go unrecognized, a major contributor is likely to be a lack of appreciation among the general population of the importance of blood pressure control. Greater awareness in the community of the risks of hypertension could contribute to increased consultations for blood pressure measurements and recognition of hypertension. Yet, even when public awareness programs have been implemented, improvement in the knowledge of the importance of blood pressure tends to be short-lived. ${ }^{17}$ The limited duration of their impact is illustrated by a month-long media campaign in Canada about the importance of blood pressure, ${ }^{17}$ which increased the number of individuals who claimed to have high blood pressure, and also decreased the number of patients who were treated and uncontrolled, but the changes were not sustained at 6 months. Nevertheless, it is incumbent on policymakers and health care professionals to initiate a dialogue about the importance of blood pressure control.

Undertreatment of hypertension may also arise from underprescribing by physicians. This has been attributed to lack of awareness of guideline recommendations, the difficulty of matching patient preferences with guideline recommendations, low motivation and low expectancy of a beneficial outcome, physician inertia, and insufficient time or resource. Another contributor to patients with hypertension not reaching treatment goals is lack of adherence to prescribed medicines. As high blood pressure does not generally cause troublesome symptoms, patients' beliefs about the necessity of taking a drug may affect adherence. Similarly, side effects experienced when patients initially take medication may cause them to view the medication unfavorably and so decrease their likelihood of taking it in the long term. Patients may deliberately not take their medication because of concerns over the possibility of side effects, particularly if they do not have troublesome symptoms of hypertension. Some patients may unintentionally forget to take their medication, which may be compounded by the complexity of the regimen. Compliance with treatment may be further affected if the patient is taking a large number of medications; a situation that is particularly common in elderly patients. Therefore, physicians should be alert to poor adherence and seek to improve it by engaging patients, emphasizing the benefits of treatment, and making the regimen as simple as possible.

\section{Improving adherence to antihypertensive therapy}

Adherence to a treatment regimen is greater with once-daily therapy than with more complex regimens, but once-daily treatment requires an agent that provides antihypertensive efficacy throughout the 24-h dosing interval. This is especially important for patients who take their medication early in the morning as blood pressure is lowest at night during sleep, with a sudden sharp increase in the early morning upon 
waking (the early morning blood pressure surge [EMBPS]). ${ }^{18}$ The significance of this surge in blood pressure is suggested by the higher incidence of cardiovascular events during the morning than at any other time. ${ }^{19-21}$ A high EMBPS predisposes individuals to target-organ damage, ${ }^{22,23}$ and cardio- and cerebrovascular events. ${ }^{24,25}$

Even in hypertensive patients receiving and adhering to treatment, the goal of achieving blood pressure control can be elusive. The use of an agent that provides powerful drug pressure reductions should be a first step in treating hypertension. Increasing the dose of antihypertensive monotherapy may control blood pressure in some individuals. However, the risk of side effects increases with increasing doses for diuretics, $\beta$-blockers, and calcium channel blockers. Thus, titrating the dose to control blood pressure with these classes of agents may come at the cost of reduced tolerability and, consequently, adherence. Although ARBs or ACE inhibitors appear to have a wider therapeutic window, it is important to be cognizant of the side-effect profile of each type of agent (eg, the association of cough with ACE inhibitors). As most patients with hypertension will require lifelong treatment, it is essential that any antihypertensive regimen has minimal adverse effects and so does not substantially impact on quality of life.

\section{The role of combination therapy in achieving hypertension goals}

While dose titration of a single agent may normalize blood pressure in some individuals, it is likely that combination antihypertensive therapy will be required in the majority of patients to adequately control blood pressure. In the Antihypertensive and Lipid-Lowering Treatment to Prevent Heart Attack Trial (ALLHAT), the target blood pressure $(<140 / 90 \mathrm{mmHg})$ was achieved in $66 \%$ of all patients. ${ }^{26}$ More than $45 \%$ of patients were treated with at least two antihypertensive agents. The use of combination therapy was also high in the Losartan Intervention for Endpoint (LIFE) reduction in hypertension study. ${ }^{27}$ At the end of the 4-year study, $66 \%$ of patients who received losartan were on at least two drugs, as were $62 \%$ of those in the atenolol arm. The Valsartan Antihypertensive Long-term Use Evaluation (VALUE) study compared valsartan- and amlodipine-based regimens for a mean follow up of 4.2 years. ${ }^{28}$ To attain the rates of blood pressure control (ie, $<140 / 90 \mathrm{mmHg}$ ) observed in the valsartan and amlodipine arms (56\% vs $62 \%$ of patients, respectively), a substantial number of patients in each study arm required at least two agents (47.6\% vs $40.6 \%$, respectively). Consistent with the evidence from these randomized, controlled trials, combination therapy has also been shown to be required to bring blood pressure under control in population surveys. For example, in a 12-year observational investigation (1984-1996) of a cohort of 940 hypertensive patients in the Brisighella Heart Study (BHS) in Italy, the proportion of patients treated for hypertension rose from $43.8 \%$ to $50.3 \%$ in men and $50 \%$ to $56.6 \%$ in women. The rate of blood pressure control more than doubled $(7.5 \%$ to $17.4 \%$ in men and from $7.3 \%$ to $18.5 \%$ in women), and was attributed to the increased use of combination therapy. ${ }^{12}$

The evidence from observational studies and clinical trials that combination therapy is often required to normalize blood pressure has informed US and European guidelines that recommend this therapeutic approach as a first-line option. ${ }^{1,3}$ In principle, the combination of two antihypertensive agents that have different mechanisms of action should provide greater antihypertensive efficacy than when each component is used individually. However, other advantages can also ensue. For example, lower doses of the individual components may decrease the likelihood of a side effect, while complementary actions may prevent side effects. The edema that can accompany calcium channel blocker use is ameliorated by concomitant use of an ARB or an ACE inhibitor, and the unwanted metabolic effects of diuretics can also be offset by combination with an ARB or ACE inhibitor. A further consideration is the impact of combination therapy on adherence; it is possible that a patient will be more adherent with a fixed-dose single tablet combination rather than a regimen that involves a combination of several individual agents. ${ }^{29}$

\section{The evidence for effects beyond blood pressure-lowering}

Evidence for the reduction in cardiovascular, cerebrovascular, and renal events with ARBs and ACE inhibitors comes from large-scale outcomes trials (Table 1). Alongside the recognition that the reduction in blood pressure is a necessary goal, there are indications that agents acting on the reninangiotensin system (RAS) have blood pressure-independent effects that may contribute to the risk reduction.

\section{Cardiovascular protection: myocardial infarction}

The Heart Outcomes Prevention Evaluation (HOPE) and LIFE studies support the hypothesis that antihypertensive agents may have beneficial effects beyond their blood pressure-lowering effects. In the former, there was a $20 \%$ reduction in the relative risk of myocardial infarction with 


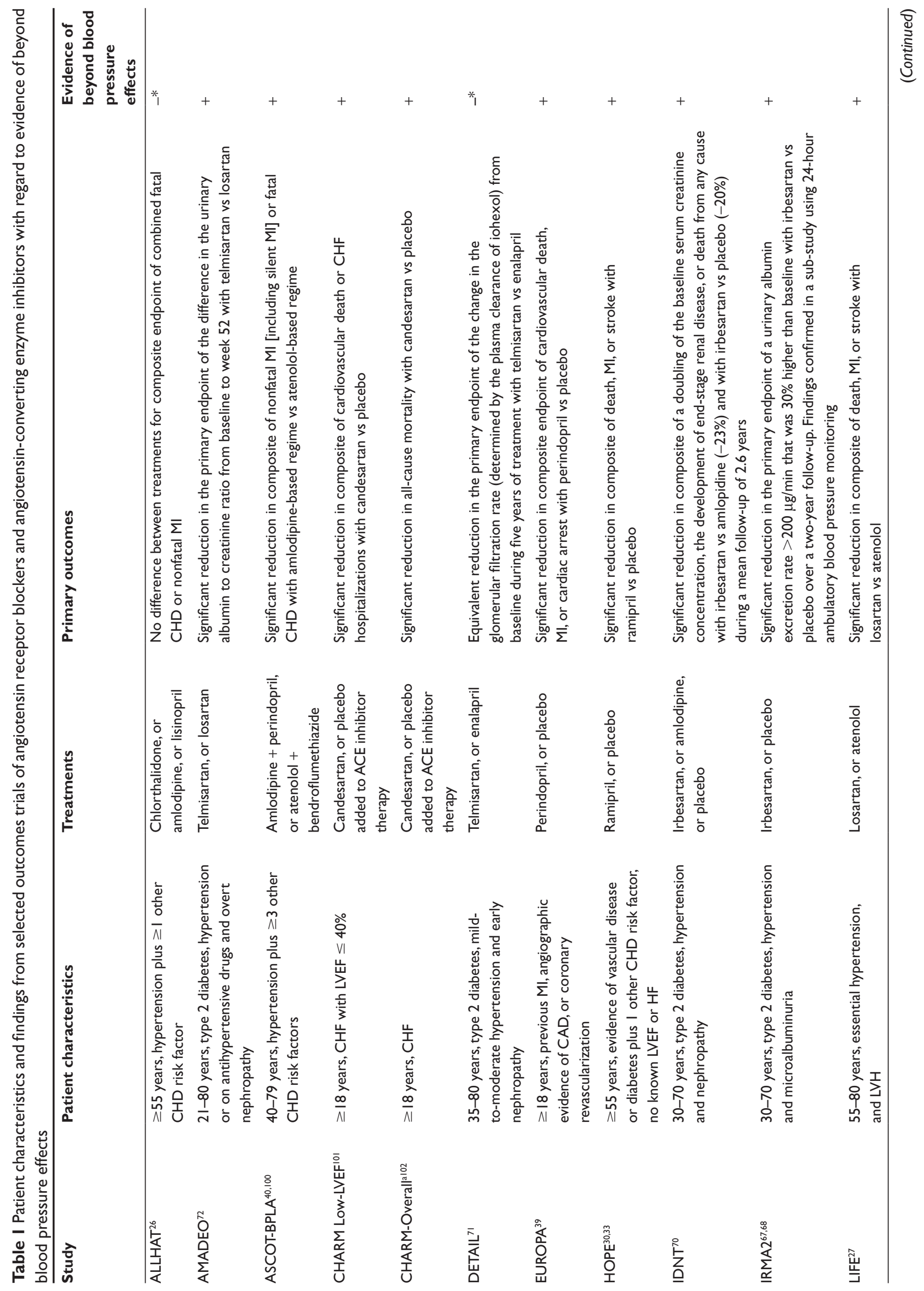




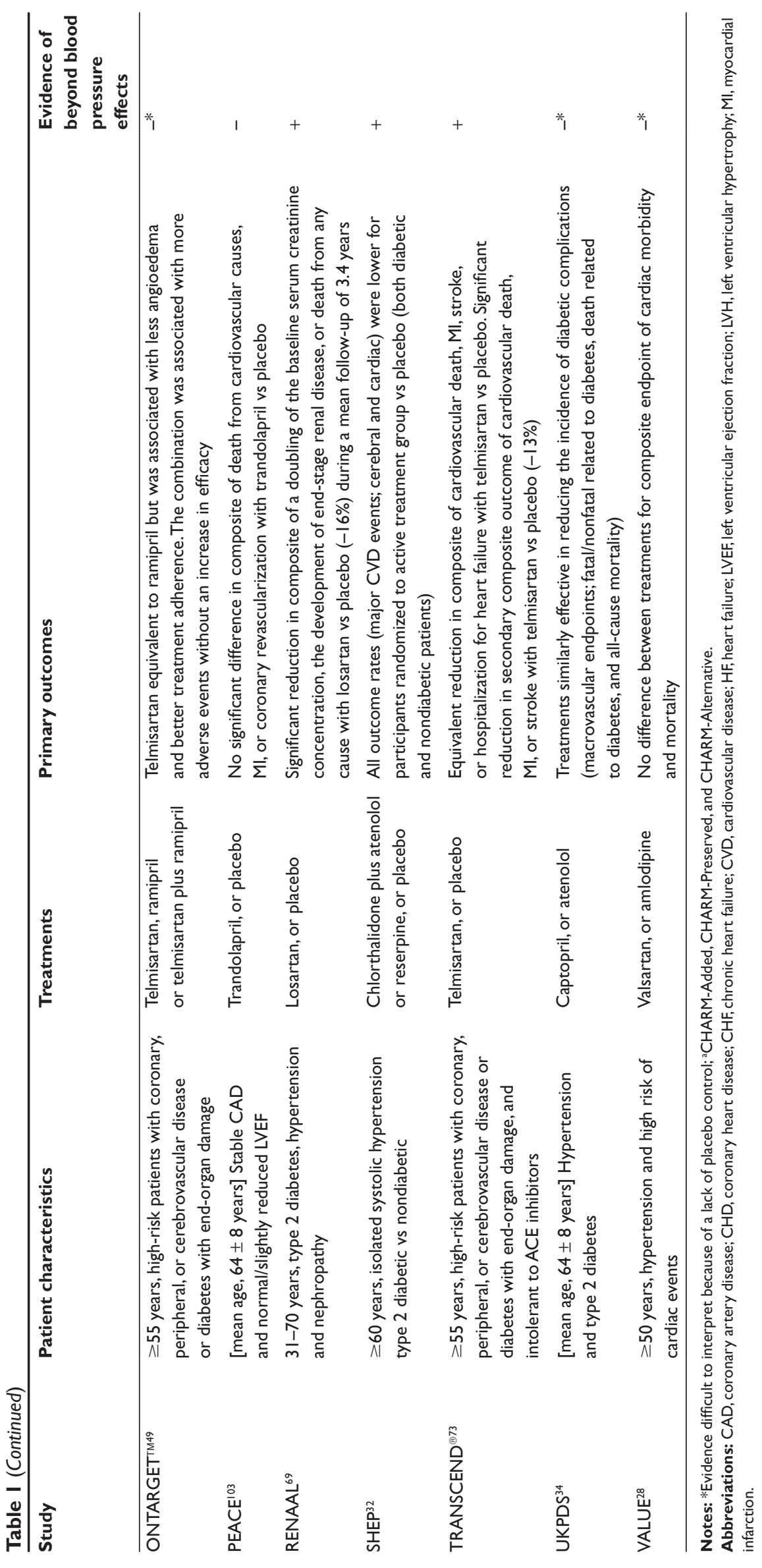


ramipril treatment compared with placebo. ${ }^{30}$ Ramipril reduced blood pressure by 3.3/1.4 mmHg in the HOPE study. Extrapolations from the Collins and MacMahon analysis suggest that this reduction in blood pressure would be expected to reduce the incidence of myocardial infarction by approximately $5 \%{ }^{31}$ It is possible that the high-risk population in HOPE may have been at greater risk of a vascular event for a given level of blood pressure than the low-risk populations in the analysis by Collins and MacMahon. However, the risk reduction in the ramipril arm was greater than would have been inferred from the relationship between blood pressure and risk in the placebo arm. The reduction in vascular events in the HOPE study was also greater than would have been anticipated from the results of the Systolic Hypertension in the Elderly Program (SHEP) study in which there was a blood pressure reduction of $10 / 2 \mathrm{mmHg}$ and a lowering in risk of a cardiovascular event by $34 \% .{ }^{32}$ Furthermore, the effects of ramipril were considered to be greater than those attributable to blood pressure-lowering alone among the 3577 patients with diabetes in the HOPE study. In these patients, the reduction in blood pressure was more modest than in the overall population $(2.2 / 1.4 \mathrm{mmHg})$, but the reduction in myocardial infarction (22\%) was similar to that in all of the patients. ${ }^{33}$ In comparison, the reduction in blood pressure in the UK Prospective Diabetes Study (UKPDS) was $10 / 5 \mathrm{mmHg}$ and was accompanied by a lowering in the risk of myocardial infarction by $21 \%{ }^{34}$ It is plausible, as suggested by the authors of the HOPE publication, that the possibility of excess overnight hypertension in the placebo group may have contributed to the difference. A related explanation is that blood pressure measurements taken during the daytime may have underestimated the (nocturnal) antihypertensive effect of ramipril, which was administered as an evening dose.

In the LIFE study, there was no difference in mean blood pressure among the 9193 patients randomized to atenolol or losartan during the mean follow-up period of 4.8 years. ${ }^{27}$ However, there was a $13 \%$ reduction in the primary endpoint (stroke, myocardial infarction, or death) among patients receiving losartan compared with those allocated to atenolol. These findings suggest that the vascular protective effects of losartan are not solely due to the blood pressure-lowering effect. A counter-argument which has been posited is that the reduction in the primary endpoint was mainly driven by the excess of strokes in the atenolol group. ${ }^{35}$ It has also been suggested that $\beta$-blockers are less effective at preventing strokes than other classes of antihypertensives, as indicated by comparisons with thiazide diuretics. ${ }^{36}$ Furthermore, the results for patients with left ventricular dysfunction in the
LIFE study were in line with those that would have been expected from the relationship between risk reduction and blood pressure-lowering observed in other trials in this patient group. ${ }^{37,38}$

Further evidence of the supplemental effects beyond blood pressure is provided by the EURopean trial On reduction of cardiac events with Perindopril in stable coronary Artery disease (EUROPA) study. The reduction in cardiovascular events in the EUROPA study was greater than expected for the observed reduction in blood pressure. ${ }^{39}$ There was a mean reduction in blood pressure of $5 / 2 \mathrm{mmHg}$ with perindopril during the 4.2-year follow-up period, which was accompanied by $20 \%$ risk reduction versus placebo in the primary endpoint of cardiovascular death, myocardial infarction, or cardiac arrest. The authors of the report stated that "this implies that the specific anti-atherosclerotic effects of ACE inhibition should not be neglected". ${ }^{39}$ The modest differences in blood pressure observed between the active treatment (ie, amlodipine plus perindopril) and comparator in the Anglo-Scandinavian Cardiac Outcomes Trial-Blood Pressure Lowering Arm (ASCOT-BPLA) study may also not account for the greater effect of treatment on cardiac event rates. ${ }^{40}$ However, higher high-density lipoprotein cholesterol levels in the ACE inhibitor plus calcium channel blocker treatment arm of the ASCOT-BPLA study may have contributed to the better coronary heart disease outcomes.

In the VALUE study, there was a blood pressure-lowering advantage with amlodipine over valsartan $(1.5 / 1.3 \mathrm{mmHg}$ after 1 year). ${ }^{28}$ Despite this difference, the incidence of cardiac morbidity and mortality was not significantly different between the two treatment groups (10.6\% valsartan vs $10.4 \%$ amlodipine, $P=0.49$ ). There was a $19 \%$ higher risk of myocardial infarction in the valsartan group compared with the amlodipine group. ${ }^{28}$ This difference was most marked in the high-risk coronary population in the study, among whom $79 \%$ of the excess myocardial infarctions occurred during the first two years of the study. Subsequently, the differences between the two groups were less apparent. This has led to the suggestion that recommended blood pressure goals need to be achieved rapidly, especially in high-risk individuals, to avoid serious vascular events..$^{28}$ Nevertheless, an editorial controversially stated that the increased incidence of myocardial infarction with valsartan in the VALUE trial could not be accounted for by the difference in blood pressure between treatments and that ARBs "may have harmful as well as beneficial effects". ${ }^{41}$ The editorial led to several systematic reviews of randomized clinical trials, three of which found that treatment with ARBs was not associated with a 
significantly increased risk of myocardial infarction. ${ }^{42-44}$ The view of other authors is that ARBs may have a neutral effect on the risk of myocardial infarction ${ }^{45}$ or may increase the risk. ${ }^{46}$ The Blood Pressure Lowering Treatment Trialists' Collaboration (BPLTTC) analyzed 26 clinical trials and concluded that there was no convincing effect of an adverse effect of ARBs on any major cardiovascular outcome. ${ }^{47}$ Recently, the UMPIRE study demonstrated that ARBs offer similar reductions in acute coronary syndrome hospitalization to ACE inhibitors (adjusted relative risk [RR] 0.89; 95\% confidence interval [CI]: 0.76-1.04), and comparable rates of myocardial infarction, one of the secondary analyses (RR 0.84; 95\% CI: 0.71-1.01). ${ }^{48}$ The ONgoing Telmisartan Alone and in combination with Ramipril Global Endpoint Trial (ONTARGET $^{\mathrm{TM}}$ ), which was conducted in 25,620 patients at high risk for vascular events, provides definitive evidence that the risk of myocardial infarction does not differ with ARB or ACE inhibitor treatment. ${ }^{49}$ The risk ratio of myocardial infarction for telmisartan, the ARB, compared with ramipril was 1.07 (95\% CI: 0.94-1.22) in this broad-spectrum, highrisk population.

\section{Cardiovascular protection: heart failure}

There was a trend for fewer admissions for heart failure with valsartan than among patients receiving the amlodipine-based regimen in the VALUE study. ${ }^{28}$ Although the difference was not significant, it is consistent with a meta-analysis which found that antihypertensive agents that block the RAS appear to be associated with a reduction in heart failure compared with other drugs, including calcium channel blockers. ${ }^{50}$ Heart failure occurred more frequently with amlodipine than with lisinopril (6-year rate: $10.2 \%$ vs $7.7 \%$ ) in the ALLHAT study. ${ }^{26}$ However, this may have been partly attributable to the misdiagnosis of peripheral edema in the amlodipine group as heart failure. It has been speculated that the difference between the two drug classes may arise from excessive sympathetic activation observed with calcium channel blockers or that the reduction in sympathetic activation noted with $\mathrm{ARBs}^{51}$ may have a beneficial effect. Additionally, the potential cardioprotective effects of ARBs could theoretically contribute to this difference.

Whether or not there are differences between active regimens on heart failure has been investigated further in prospectively designed overviews of randomized trials by the BPLTTC. In one of the earliest analyses, regimens based on ACE inhibitors, diuretics, or $\beta$-blockers were found to be more effective at preventing heart failure than those based on calcium channel blockers. ${ }^{52}$ In a subsequent analysis, ARBs appeared to afford greater protection against heart failure in patients with diabetes compared with patients without diabetes; this difference was not apparent for other classes. ${ }^{53}$ In its latest analysis, the BPLTTC found that ARBs and ACE inhibitors gave similar reductions in heart failure risk, and neither class had an effect on heart failure beyond that attributable to blood pressure-lowering. ${ }^{47}$ The Irbesartan in Heart Failure with Preserved Systolic Function (I-PRESERVE) trial that was conducted in patients with heart failure with a preserved left ventricular ejection fraction ( $\geq 45 \%$ ) showed that irbesartan did not improve any of the pre-specified outcomes, including the primary composite outcome of death from any cause or hospitalization for cardiovascular disease (heart failure, myocardial infarction, unstable angina, arrhythmia, or stroke)..$^{54}$

\section{Cardiovascular protection: atrial fibrillation}

Inhibition of the RAS with either ARBs or ACE inhibitors has been shown to prevent new onset and recurrence of atrial fibrillation in different patient populations. Among patients without previous atrial fibrillation, losartan reduced the incidence of new onset atrial fibrillation in the LIFE study. ${ }^{55}$ In hypertensive patients requiring antiarrhythmic therapy, irbesartan in association with amiodarone was found to reduce the recurrence of atrial fibrillation. ${ }^{56}$ In our study, we found that telmisartan decreased the incidence of recurrence of atrial fibrillation in hypertensive patients not requiring antiarrhythmic therapy compared with carvedilol. ${ }^{57}$ Atrial fibrillation was reported in $14.2 \%(10 / 70)$ of patients in the telmisartan group compared with $37 \%(23 / 62)$ of those in the carvedilol group $(P<0.003)$. Furthermore, the recurrence of atrial fibrillation was delayed in the telmisartan group compared with the carvedilol group. Recent evidence from the Atrial fibrillation Clopidogrel Trial with Irbesartan for prevention of Vascular Events (ACTIVE-I), which investigated patients with atrial fibrillation and at least one other risk factor, showed no advantage for the primary outcome of cardiovascular death, stroke, or myocardial infarction. ${ }^{58}$ However, irbesartan did reduce hospitalizations due to heart failure by $14 \%(P=0.018)$, a common complication of atrial fibrillation. ${ }^{58}$

The RAS can facilitate the onset and recurrence of atrial fibrillation by increasing blood pressure and intracavitary atrial pressure and though arrhythmogenic atrial remodeling. Both ARBs and ACE inhibitors may prevent atrial fibrillation through lowering end-diastolic left ventricular pressure and subsequently left atrial pressure, thereby decreasing atrial 
stretch and dilatation. Experimental models have shown that blockade of the RAS may attenuate atrial functional remodeling that disposes to atrial fibrillation.

There is initial evidence that some of the protective effect of these agents is due to actions on pathophysiological mechanisms other than elevated blood pressure. In trials with blockers of the RAS, such as TRACE ${ }^{59}$ and a sub-study from SOLVD,${ }^{60}$ there was no placebo control and it is not possible to determine whether the effect on atrial fibrillation is the result of the blood pressure reduction per se or if the effect is specific to blocking of the RAS. However, in the LIFE trial, atenolol and losartan had similar blood pressure-lowering capabilities, suggesting that antihypertensive efficacy is not the whole issue with respect to differences seen in new-onset atrial fibrillation. ${ }^{55}$ The difference between telmisartan and carvedilol on atrial fibrillation that we have reported was not related to change in blood pressure, left atrial size, and left ventricular hypertrophy. ${ }^{57}$

Apart from blood pressure reduction, there are other potential mechanisms by which inhibition of the RAS may reduce atrial fibrillation. Atrial fibrillation produces significant changes in atrial tissue and the interstitial matrix, increasing the amount of fibrous tissue and collagen accumulation. ${ }^{61}$ These tissue changes can provide a substrate that increases the likelihood of atrial fibrillation recurrence. One mediator responsible for these changes is angiotensin II. ${ }^{62}$ ARBs have been shown to inhibit collagen type I synthesis and cause regression of myocardial fibrosis and to reduce collagen deposition in the atria. The reduction in the amount of fibrous tissue may limit heterogeneity and delay in atrial activation.

Another mechanism through which blockade of the RAS may affect atrial fibrillation is due to anti-inflammatory effects. In addition, the RAS can also facilitate coronary atherosclerosis, increase reactive oxygen species, and induce atrial fibrosis. It is also possible that the elevation of atrial pressure might cause electrical remodeling by upregulation of atrial angiotensin type 1 ( $\left.\mathrm{AT}_{1}\right)$ receptor expression. ${ }^{63}$ Blockade of local angiotensin II by ACE inhibitors and ARBs could attenuate atrial fibrillation-induced electrical remodeling, probably by preventing calcium overload. Genetic variation in the RAS is also seen to be associated with atrial fibrillation, providing further evidence of the important role of RAS and the possibly beneficial effect of RAS blockade.

\section{Cerebrovascular protection}

In the HOPE study, there was $32 \%$ reduction in the relative risk of stroke with ramipril treatment compared with placebo. ${ }^{30}$ Extrapolations from the Collins and MacMahon analysis suggest that the reduction in blood pressure achieved in the study would be expected to reduce the incidence of stroke by approximately $13 \% .{ }^{31}$ Furthermore, these beyond blood pressure-lowering effects of ramipril were also observed in the patients with diabetes in the HOPE study, who had more modest reductions in blood pressure than in the overall population $(2.2 / 1.4 \mathrm{mmHg})$, but the reduction in stroke (33\%) was similar to that in all of the patients. ${ }^{33}$ Further support comes from the UKPDS, which showed that a blood pressure reduction of $10 / 5 \mathrm{mmHg}$ was accompanied by a lowering of the risk of stroke by $44 \%{ }^{34}$ In the LIFE study, there was no difference in mean blood pressure among the 9193 patients randomized to atenolol or losartan during the mean follow-up period of 4.8 years. ${ }^{27}$ However, there was a $25 \%$ reduction in the risk of stroke among patients receiving losartan compared with those allocated to atenolol. ${ }^{27}$ These findings suggest that the cerebrovascular protective effects of losartan are not solely due to the blood pressure-lowering effect, but as previously discussed, alternate explanations for the $13 \%$ reduction in the primary endpoint (stroke, myocardial infarction, or death) and the risk of stroke have been posited..$^{35,36}$

ARBs and ACE inhibitors appear to improve cardiovascular outcomes in comparison with other agents, but in both the ALLHAT and VALUE studies, the incidence of stroke was lower in the amlodipine treatment arms than in the lisinopril and valsartan arms, respectively. ${ }^{26,28}$ Stroke is a complication of hypertension that has a direct relationship with the level of blood pressure ${ }^{64} \mathrm{~A} 10 \mathrm{mmHg}$ increase in systolic or $5 \mathrm{mmHg}$ increase in diastolic hypertension increases the risk of stroke by $30 \%$ and $20 \%$, respectively. ${ }^{65}$ A seminal analysis by Collins and MacMahon documented that a 5-6 $\mathrm{mmHg}$ reduction in blood pressure maintained over 5 years reduces the incidence of stroke by approximately $40 \% .{ }^{31}$ Subsequent to the work by Collins and MacMahon, meta-analyses of largescale, active-controlled studies have indicated that lowering blood pressure reduces the risk of a cerebrovascular event. ${ }^{52,66}$ Thus, small differences in the level of blood pressure control may explain some of the differences in the incidence of stroke observed between calcium channel blockers and ARBs or ACE inhibitors. This difference is likely to be attributable to the greatest reductions in blood pressure (eg, the difference in systolic blood pressure was $1.2 \mathrm{mmHg}$ at 5 years in ALLHAT; $1.5 / 1.3 \mathrm{mmHg}$ difference after 1 year in VALUE). ${ }^{26,28}$ This emphasizes the importance of effective and aggressive blood pressure control. Yet there may be differences between agents in their effects on stroke that are specific to particular 
classes. In an overview by the BPLTTC, there was a greater effect of calcium channel blocker-based regimens on stroke compared with regimens based on diuretics or $\beta$-blockers, but the result was of borderline significance. ${ }^{52}$ There was also a trend towards greater reductions in stroke risk with regimens based on calcium channel blockers and diuretics or $\beta$-blockers than with regimens based on ACE inhibitors. In another analysis, by Verdecchia and colleagues, calcium channel blockers appeared to be more effective than ACE inhibitors for the prevention of stroke. ${ }^{66}$

\section{Renal protection}

RAS inhibition with either ARBs or ACE inhibitors has been shown to reduce proteinuria and end-stage renal disease (ESRD). In the IRbesartan in patients with type 2 diabetes and MicroAlbuminuria (IRMA2) study, which investigated whether or not an ARB (added to a background of other hypertensive agents) could delay or prevent the development of diabetic nephropathy in hypertensive patients with type 2 diabetes and persistent microalbuminuria, $14.9 \%$, $9.7 \%$, and $5.2 \%$ of the placebo, irbesartan $150 \mathrm{mg}$, and irbesartan $300 \mathrm{mg}$ groups, respectively, reached the primary endpoint of a urinary albumin excretion rate (UAER) $>200 \mu \mathrm{g} / \mathrm{min}$ and $\geq 30 \%$ higher than the baseline value. ${ }^{67}$ In this study, persistent microalbuminuria was defined as a UAER of $20-200 \mu \mathrm{g} / \mathrm{min}$ in two of three consecutive overnight urine samples. Normoalbuminuria was also more frequently restored in patients receiving irbesartan $300 \mathrm{mg}$. As there were no significant differences in the blood pressure-lowering effects between the three groups, the authors concluded that the beneficial effects of the ARB appeared to be independent of blood pressure-lowering. ${ }^{67}$ A sub-study measuring 24-hour ambulatory blood pressure in 43 patients confirmed these findings. ${ }^{68}$

In the Reduction of Endpoints in Non-insulin-dependent diabetes mellitus with the Angiotensin II Antagonist Losar$\tan$ (RENAAL) study, double-blind losartan 50-100 mg in addition to conventional antihypertensive therapy was associated with a significant $16 \%(P=0.02)$ risk reduction versus placebo in the composite primary endpoint of a doubling of serum creatinine, ESRD, or death over a mean treatment period of 3.4 years. ${ }^{69}$ The risk reduction was due to losartan reducing the incidence of the doubling of serum creatinine and ESRD, rather than reductions in mortality. The beneficial effect of losartan on the renal endpoints was considered to be greater than that due to blood pressure reductions alone.
The Irbesartan in Diabetic Nephropathy (IDNT) study directly compared irbesartan with the calcium channel blocker amlopidine in type 2 diabetes patients receiving additional antihypertensive drugs to achieve the target SBP/DBP of $135 / 85 \mathrm{mmHg} .{ }^{70}$ The composite primary endpoint was a doubling of serum creatinine, ESRD, or death. ${ }^{70}$ Irbesartan significantly reduced the risk of the primary endpoint by $20 \%$ and $23 \%(P=0.02 ; P=0.006)$ compared with placebo and amlodipine, respectively, over the mean follow-up of 2.6 years. ${ }^{70}$ The authors concluded that the protection against nephropathy provided by irbesartan was independent of its blood pressure-lowering effects.

The Diabetics Exposed to Telmisartan And enalaprIL (DETAIL) study was a head-to-head comparison of an ACE inhibitor and an ARB in patients with type 2 diabetes with early nephropathy who received either telmisartan or enalapril for up to five years. ${ }^{71}$ Under pre-specified conditions (seated DBP was $>100 \mathrm{mmHg}$ or $\mathrm{SBP}$ was $>160 \mathrm{mmHg}$ ) additional antihypertensive therapy was permitted after two months of double-blind treatment. The primary endpoint was the change in glomerular filtration rate from baseline. Based on the primary outcome, the study demonstrated the noninferiority of telmisartan compared with enalapril. ${ }^{71}$ The findings of the DETAIL study supported the clinical equivalence of ARBs and ACE inhibitors for long-term renal protection in patients with type 2 diabetes and early nephropathy.

In the telMisartan versus losArtan in hypertensive type 2 DiabEtic patients with Overt nephropathy (AMADEO) study, a head-to-head comparison of two ARBs, despite similar blood pressure reductions after 52 weeks of treatment, telmisartan was associated with significantly greater reductions in the primary endpoint (the difference in the urinary protein-to-creatinine ratio) compared with losartan $(P=0.03) .^{72}$

\section{Cardiovascular protection: broad high risk population}

ONTARGET $^{\mathrm{TM}}$ is the largest outcome study ever performed with an ARB, and the only one to demonstrate protective efficacy in a broad cross-section of patients at high risk of vascular events (ie, with atherothrombotic cardiovascular disease, or type 2 diabetes with target-organ damage). ${ }^{49}$ It compared telmisartan monotherapy with ramipril monotherapy as well as comparing the combination of telmisartan and ramipril with ramipril monotherapy. Patients were either nonhypertensive or had controlled hypertension at baseline, and received 
concomitant antihypertensives as needed, ensuring that blood pressure differences did not influence the results. There was no difference in primary outcome (a composite of cardiovascular mortality, nonfatal myocardial infarction, nonfatal stroke, and hospitalization for chronic heart failure) between telmisartan and ramipril (occurring in 1423 patients [16.7\%] and 1412 patients [16.5\%], respectively). ${ }^{49}$ Telmisartan was better tolerated and associated with a higher compliance rate than ramipril over the course of the 56-week study.

The effect of telmisartan on cardiovascular morbidity in patients intolerant of ACE inhibitors was evaluated in TRANSCEND ${ }^{\circledR}{ }^{73}$ As in ONTARGET, patients were at high risk of vascular disease, but in TRANSCEND the comparator was placebo on a background of best standard of care. ${ }^{73}$ There was no significant difference in the primary outcome (which included hospitalizations for heart failure) between the study arms, but telmisartan significantly lowered the risk of the HOPE study outcome (ie, a composite of cardiovascular death, myocardial infarction, or stroke) by $13 \%$. $^{73}$ This reduction occurred against a background of non-ARB/ ACEI therapy that was significantly more intensive than in the HOPE trial, and which meant that the event rate in the placebo arm was relatively low. Remarkably, adherence was better with telmisartan than for patients on best standard of care, which may be a consequence of higher concomitant medication use in the placebo arm.

\section{Confounding factors to consider when comparing studies}

An important caveat when comparing outcomes from the studies discussed above is that patient populations may be subtly or markedly different, depending on each study's inclusion and exclusion criteria (Table 1). The influence of patient population characteristics is illustrated by a systematic review by Dagenais and colleagues of three large outcome studies (HOPE, EUROPA, and Prevention of Events with Angiotensin-Converting Enyzme inhibition [PEACE]). ${ }^{74}$ The analysis evaluated the effect of ACE inhibition on cardiovascular outcomes and mortality in patients who had stable vascular disease without left ventricular systolic dysfunction. ACE inhibition reduced all-cause mortality (7.8\% vs $8.9 \%, P=0.0004)$, cardiovascular mortality $(4.3 \%$ vs $5.2 \%, P=0.0002)$, all stroke ( $2.2 \%$ vs $2.8 \%, P=0.0004)$, and other endpoints such as nonfatal myocardial infarction, heart failure, and coronary-artery bypass surgery. There was a relative $18 \%$ risk reduction in the composite endpoint of cardiovascular mortality, nonfatal myocardial infarction, and stroke for patients receiving an ACE inhibitor compared with those allocated to placebo. A subsequent systematic review also reported that ACE inhibitors reduce total mortality and major cardiovascular endpoints, including stroke, in patients who have coronary artery disease and no heart failure or left ventricular systolic dysfunction. ${ }^{75}$

In the publication by Dagenais, analyses were also performed on data from five long-term studies in patients who had heart failure or left ventricular systolic dysfunction. ${ }^{74}$ The outcomes in the patients with stable vascular disease were generally similar to those in patients with heart failure or left ventricular systolic dysfunction. For example, the relative $18 \%$ risk reduction in the composite endpoint of cardiovascular mortality, nonfatal myocardial infarction, and stroke was similar to the $21 \%$ determined in the higherrisk patient group. However, although the analysis of the HOPE, EUROPA, and PEACE studies showed a clear benefit of ACE inhibition on stroke, this effect was not apparent among patients with heart failure or left ventricular systolic dysfunction. It was suggested that this finding may be due to the lower initial blood pressure of patients in these trials, the low degree of blood pressure-lowering among them, and the relatively low event rates.

The VALsartan In Diastolic Dysfunction (VALIDD) trial further illustrates the importance of the characteristics of the patient population and confounding factors. ${ }^{76}$ The study was based on the premise that ARBs reduce left ventricular hypertrophy and myocardial fibrosis. Patients with diastolic dysfunction were randomized to either valsartan or placebo for 38 weeks. In addition, they received add-on therapy that did not act on the RAS to reach targets of $<135 / 85 \mathrm{mmHg}$. There were no significant differences in measures of changes in diastolic function between the two treatment groups. This indicates that blood pressure-lowering alone was responsible for the improvements in diastolic function. An accompanying commentary cautioned that the results should be interpreted in the context of the design of the study and of the patient population. ${ }^{77}$ The prevalence of left ventricular hypertrophy, and thus of myocardial fibrosis, in the study population was low. In addition, the effect of the ARB on sympathetic activation may have been ameliorated in the third of the population that was taking concomitant $\beta$-blockers. The authors of the commentary did not exclude the potential benefits of valsartan in the population and recommended larger trials with longer-term follow-up to test whether ARBs improve cardiac function independently of blood pressure control. 


\section{Summary}

It is not certain to what extent effects beyond blood pressure influence cardiovascular, cerebrovascular, and renal outcomes. The accumulated evidence from the clinical studies outlined above suggests, but does not prove, that ACE inhibitors and ARBs provide greater reductions in these outcomes than can be attributed to blood pressure-lowering alone. The overall conclusion of the BPLTTC from its analyses is that blood pressure reduction has a central role in producing the benefits observed. ${ }^{53}$ Moreover, it concluded that there was evidence that ACE inhibitors but not ARBs had blood pressure-independent effects on the risk of major coronary events. ${ }^{47}$ However, they did not exclude an effect of ARBs on macrovascular risk.

The comparisons between studies from which these inferences are drawn are limited by differences in design, study populations, and baseline blood pressures. These differences confound the ability to differentiate blood pressure-dependent effects from those that are due to effects beyond blood pressure reduction. Nevertheless, the evidence suggests that there are differences due to effects beyond those attributable to blood pressure reduction alone.

\section{Clinical effects of the combination of an ARB and ACE inhibitor}

ACE inhibitors and ARBs have mechanistically distinct actions that have been hypothesized to have clinically relevant consequences. The $\mathrm{AT}_{1}$ receptor mediates several pathophysiological effects. ${ }^{78}$ Interrupting its vasoconstrictive and osmoregulatory effects contributes to the antihypertensive effects of ARBs and ACE inhibitors. The $\mathrm{AT}_{1}$ receptor is also associated with endothelial dysfunction through lipid peroxidation, free radical production, smooth muscle and extracellular matrix proliferation, and expression of proinflammatory genes (eg, chemoattractant proteins, leukocyte adhesion molecules, adhesion, and cytokines). ${ }^{79-82}$

ACE inhibition prevents the degradation of bradykinin and the accumulation of bradykinin has been implicated in the beneficial cardiovascular effects of ACE inhibitors. ${ }^{83-89}$ However, the increase in levels of bradykinin may not be totally advantageous as it has been linked to the increased incidence of cough seen with ACE inhibitors, although other mechanisms are also likely to be involved in ACE inhibitor-induced cough..$^{90}$ Another potential issue with ACE inhibitors is that high or maximally recommended doses of ACE inhibitors do not completely prevent angiotensin II formation, ${ }^{91,92}$ which suggests the involvement of alternative mechanisms (eg, tissue chymases) for converting angioten$\sin$ I to angiotensin II.

ARBs prevent the activation of the $\mathrm{AT}_{1}$ receptor but, in contrast to ACE inhibitors, they do not prevent the potentially beneficial effects of modulation of the angiotensin type 2 $\left(\mathrm{AT}_{2}\right)$ receptor by angiotensin II. ${ }^{78}$ The function of the $\mathrm{AT}_{2}$ receptor is less well understood than that of the $\mathrm{AT}_{1}$ receptor, but some of its actions oppose those of the $\mathrm{AT}_{1}$ receptor and it has been hypothesized that these actions contribute to the vascular protective effects of ARBs.

The prospect of more complete RAS blockade that can be provided by a combination of an ARB and an ACE inhibitor is the basis for the suggestion that the combination may provide greater cardiovascular protection than the component monotherapies. In a meta-analysis of randomized, controlled trials, the combination of an ARB and an ACE inhibitor reduced ambulatory blood pressure by $4.7 / 3.0 \mathrm{mmHg}$ compared with ACE inhibitor monotherapy and by $3.8 / 2.9 \mathrm{mmHg}$ compared with ARB monotherapy. ${ }^{93}$ However, the majority of these studies used submaximal doses or once-daily dosing of shorter-acting ACE inhibitors; when a larger dose of shorter-acting ACE inhibitor or a longer-acting ACE inhibitor was used, there was generally no additive effect of the ARB on blood pressure. Additionally, the number of patients on combination therapy was small (10-99 patients), the studies were relatively short-term ( $<12$ weeks), and only three trials had uncomplicated hypertension as an entry criterion.

There is some evidence from small-scale studies that a combination of an ARB and an ACE inhibitor beneficially affects markers of cardiovascular risk. ${ }^{94-96}$ Large outcome studies have investigated the effects of dual RAS control on cardiovascular endpoints but the general applicability of these findings is limited because they have been performed in different populations and considered different endpoints. ${ }^{37,97,98}$ In the Candesartan in Heart failure: Assessment of Reduction in Mortality and morbidity (CHARM)-Added Trial, patients with New York Heart Association (NYHA) II-IV congestive heart failure and left ventricular ejection fraction $<40 \%$ were randomized to ACE inhibitor therapy and additional candesartan or placebo. ${ }^{98}$ Over a median follow-up period of 41 months, candesartan significantly reduced the number of patients who experienced the composite primary outcome of cardiovascular death or hospitalization for chronic heart failure compared with placebo ( $38 \%$ vs $42 \%$, respectively). The Valsartan HEart Failure Trial (Val-HEFT) also found that ARB and ACE inhibitor combination therapy improves outcomes. ${ }^{97}$ In contrast, the VALsartan In Acute myocardial 
iNfarction Trial (VALIANT) found that all-cause mortality was similar among its three treatment arms (valsartan, captopril, or the combination) over the median 24.7-month follow-up period in patients with left ventricular dysfunction or heart failure after myocardial infarction. ${ }^{37}$ In ONTARGET, combination therapy with telmisartan and ramipril provided no additional benefit to ramipril monotherapy (ie, the primary endpoint occurred in 1386 [16.3\%] combination-treated patients) and was associated with a higher incidence of adverse events than ramipril. ${ }^{49}$ The ESH recently reappraised the $2007 \mathrm{ESH} / \mathrm{ESC}$ guidelines, ${ }^{3}$ and in light of the ONTARGET $^{\mathrm{TM}}$ findings, warned against the use of ARBs combined with ACE inhibitors, at least in patients with very high cardiovascular risk, such as those in ONTARGET ${ }^{\mathrm{TM}} \cdot{ }^{99}$

\section{Conclusion}

There is overwhelming evidence that hypertension increases the risk of cardiovascular complications and that control of blood pressure reduces this risk. Yet, despite some improvements in hypertension awareness and management, control of hypertension remains suboptimal. Achieving greater rates of blood pressure control in patients will reduce cardiovascular morbidity and mortality. This goal has many inherent challenges but some of these can be overcome by raising awareness of the impact of hypertension, using effective therapies either as monotherapy or in combination as required, and through treatment approaches that maximize adherence. All classes of antihypertensive agents have been shown to provide end-organ protection in large outcome studies. A number of placebo-controlled studies, including HOPE, EUROPA, IDNT, IRMA2, RENAAL, and TRANSCEND ${ }^{\circledR}$, support the hypothesis that antihypertensive agents may have beneficial effects beyond their blood pressure-lowering effects. A number of other studies, including AMADEO, DETAIL, LIFE, and ONTARGET ${ }^{\mathrm{TM}}$, which compared active agents in populations that were already receiving other antihypertensive therapies demonstrated effects over and above good blood pressure control. In agents showing equivalent cardiovascular, cerebrovascular, and renal protective effects, agents offering better tolerability and increased patient adherence may be advantageous for the long-term management of hypertension and reduction of cardiovascular morbidity. This is particularly relevant when considering those studies in which ARBs and ACEIs have shown equivalent protection in patients screened for ACEI intolerance, such as the ONTARGET study. Thus, these and other clinical studies suggest that particular classes of antihypertensive therapy may have beneficial effects separate from their effects on blood pressure.

\section{Acknowledgments}

Writing and editorial assistance was provided by Tom Rees, PhD of PAREXEL MedCom, which was contracted by Boehringer Ingelheim for these services. The author meets criteria for authorship as recommended by the International Committee of Medical Journal Editors (ICMJE) and was fully responsible for all content and editorial decisions, and was involved at all stages of manuscript development. The author received no compensation related to the development of the manuscript.

\section{Disclosures}

The authors report no conflicts of interest in this work.

\section{References}

1. Chobanian AV, Bakris GL, Black HR, et al. Seventh report of the Joint National Committee on Prevention, Detection, Evaluation, and Treatment of High Blood Pressure. Hypertension. 2003;42:1206-1252.

2. Rosendorff C, Black HR, Cannon CP, et al. Treatment of hypertension in the prevention and management of ischemic heart disease: a scientific statement from the American Heart Association Council for High Blood Pressure Research and the Councils on Clinical Cardiology and Epidemiology and Prevention. Circulation. 2007;115: 2761-2788.

3. Mancia G, De Backer G, Dominiczak A, et al. 2007 Guidelines for the Management of Arterial Hypertension: The Task Force for the Management of Arterial Hypertension of the European Society of Hypertension (ESH) and of the European Society of Cardiology (ESC). J Hypertens. 2007;25:1105-1187.

4. Ebrahim S, Smith GD. Lowering blood pressure: a systematic review of sustained effects of non-pharmacological interventions. J Public Health Med. 1998;20:441-448.

5. Mulrow CD, Chiquette E, Angel L, et al. Dieting to reduce body weight for controlling hypertension in adults. Cochrane Database Syst Rev. 2000;2:CD000484.

6. Fahey T, Schroeder K, Ebrahim S. Interventions used to improve control of blood pressure in patients with hypertension. Cochrane Database Syst Rev. 2006;4:CD005182.

7. Brunner HR, Stumpe KO, Januszewicz A. Antihypertensive efficacy of olmesartan medoxomil and candesartan cilexetil assessed by 24-hour ambulatory blood pressure monitoring in patients with essential hypertension. Clin Drug Investig. 2003;23:419-430.

8. Oparil S, Williams D, Chrysant SG, et al. Comparative efficacy of olmesartan, losartan, valsartan, and irbesartan in the control of essential hypertension. J Clin Hypertens (Greenwich). 2001;3:283-291, 318.

9. Hajjar I, Kotchen TA. Trends in prevalence, awareness, treatment, and control of hypertension in the United States, 1988-2000. JAMA. 2003;290:199-206.

10. Petrella RJ, Merikle EP, Jones J. Prevalence, treatment, and control of hypertension in primary care: gaps, trends, and opportunities. J Clin Hypertens (Greenwich). 2007;9:28-35.

11. Di Bari M, Salti F, Nardi M, et al. Undertreatment of hypertension in community-dwelling older adults: a drug-utilization study in Dicomano, Italy. J Hypertens. 1999;17:1633-1640.

12. Borghi C, Dormi A, D'Addato S, et al. Trends in blood pressure control and antihypertensive treatment in clinical practice: the Brisighella Heart Study. J Hypertens. 2004;22:1707-1716.

13. MacDonald TM, Morant SV, Mozaffari E. Treatment patterns of hypertension and dyslipidaemia in hypertensive patients at higher and lower risk of cardiovascular disease in primary care in the United Kingdom. J Hum Hypertens. 2007;21:925-933. 
14. van Wyk JT, Picelli G, Dieleman JP, et al. Management of hypertension and hypercholesterolaemia in primary care in The Netherlands. Curr Med Res Opin. 2005;21:839-848.

15. Sharma AM, Wittchen HU, Kirch W, et al. High prevalence and poor control of hypertension in primary care: cross-sectional study. J Hypertens. 2004;22:479-486.

16. Fagard RH, Van Den EM, Leeman M, et al. Survey on treatment of hypertension and implementation of World Health Organization/ International Society of Hypertension risk stratification in primary care in Belgium. J Hypertens. 2002;20:1297-1302.

17. Petrella RJ, Speechley M, Kleinstiver PW, et al. Impact of a social marketing media campaign on public awareness of hypertension. $\mathrm{Am}$ J Hypertens. 2005;18:270-275.

18. Millar-Craig MW, Bishop CN, Raftery EB. Circadian variation of blood-pressure. Lancet. 1978;i:795-797.

19. Elliott WJ. Circadian variation in the timing of stroke onset - a meta-analysis. Stroke. 1998;29:992-996.

20. Marler JR, Price TR, Clark GL, et al. Morning increase in onset of ischemic stroke. Stroke. 1989;20:473-476.

21. Muller JE, Stone PH, Turi ZG, et al. Circadian variation in the frequency of onset of acute myocardial infarction. $N$ Engl J Med. 1985;313: $1315-1322$

22. Gosse P, Dubourg O, Gueret P. Regression of left ventricular hypertrophy with echocardiography: some lessons from the LIVE study. J Hypertens. 2003;21:217-221.

23. Kamoi K, Miyakoshi M, Soda S, et al. Usefulness of home blood pressure measurement in the morning in type 2 diabetic patients. Diabetes Care. 2002;25:2218-2223.

24. Gosse P, Cipriano C, Bemurat L, et al. Prognostic significance of blood pressure measured on rising. J Hum Hypertens. 2001;15:413-417.

25. Kario K, Pickering TG, Umeda Y, et al. Morning surge in blood pressure as a predictor of silent and clinical cerebrovascular disease in elderly hypertensives: a prospective study. Circulation. 2003;107:1401-1406.

26. The ALLHAT Officers and Coordinators. Major outcomes in high-risk hypertensive patients randomized to angiotensin-converting enzyme inhibitor or calcium channel blocker vs diuretic. JAMA. 2002;288: 2981-2997.

27. Dahlöf B, Devereux RB, Kjeldsen SE, et al. Cardiovascular morbidity and mortality in the Losartan Intervention For Endpoint reduction in hypertension study (LIFE): a randomised trial against atenolol. Lancet. 2002;359:995-1003.

28. Julius S, Kjeldsen SE, Weber M, et al. Outcomes in hypertensive patients at high cardiovascular risk treated with regimens based on valsartan or amlodipine: the VALUE randomised trial. Lancet. 2004;363: 2022-2031.

29. Bangalore S, Kamalakkannan G, Parkar S, et al. Fixed-dose combinations improve medication compliance: a meta-analysis. Am J Med. 2007;120:713-719.

30. Yusuf S, Sleight P, Pogue J, et al. Effects of an angiotensin-convertingenzyme inhibitor, ramipril, on cardiovascular events in high-risk patients. The Heart Outcomes Prevention Evaluation Study Investigators. N Engl J Med. 2000;342:145-153.

31. Collins R, MacMahon S. Blood pressure, antihypertensive drug treatment and the risks of stroke and of coronary heart disease. Br Med Bull. 1994;50:272-298.

32. Curb JD, Pressel SL, Cutler JA, et al. Effect of diuretic-based antihypertensive treatment on cardiovascular disease risk in older diabetic patients with isolated systolic hypertension. Systolic Hypertension in the Elderly Program Cooperative Research Group. JAMA. 1996;276: 1886-1892.

33. Heart Outcomes Prevention Evaluation (HOPE) Study Investigators. Effects of ramipril on cardiovascular and microvascular outcomes in people with diabetes mellitus: results of the HOPE study and MICROHOPE substudy. Lancet. 2000;355:253-259.

34. UK Prospective Diabetes Study Group. Efficacy of atenolol and captopril in reducing risk of macrovascular and microvascular complications in type 2 diabetes: UKPDS 39. BMJ. 1998;317:713-720.
35. Staessen JA, Wang JG, Birkenhager WH. Outcome beyond blood pressure control? Eur Heart J. 2003;24:504-514.

36. Messerli FH, Grossman E, Goldbourt U. Are beta-blockers efficacious as first-line therapy for hypertension in the elderly? A systematic review. JAMA. 1998;279:1903-1907.

37. Pfeffer MA, McMurray JJ, Velazquez EJ, et al. Valsartan, captopril, or both in myocardial infarction complicated by heart failure, left ventricular dysfunction, or both. N Engl J Med. 2003;349:1893-1906.

38. Yusuf S, Pepine CJ, Garces C, et al. Effect of enalapril on myocardial infarction and unstable angina in patients with low ejection fractions. Lancet. 1992;340:1173-1178.

39. Fox KM. Efficacy of perindopril in reduction of cardiovascular events among patients with stable coronary artery disease: randomised, doubleblind, placebo-controlled, multicentre trial (the EUROPA study). Lancet. 2003;362:782-788.

40. Poulter NR, Wedel H, Dahlöf B, et al. Role of blood pressure and other variables in the differential cardiovascular event rates noted in the AngloScandinavian Cardiac Outcomes Trial-Blood Pressure Lowering Arm (ASCOT-BPLA). Lancet. 2005;366:907-913.

41. Verma S, Strauss M. Angiotensin receptor blockers and myocardial infarction. BMJ. 2004;329:1248-1249.

42. McDonald MA, Simpson SH, Ezekowitz JA, et al. Angiotensin receptor blockers and risk of myocardial infarction: systematic review. $B M J$. 2005;331:873-879.

43. Verdecchia P, Angeli F, Gattobigio R, et al. Do angiotensin II receptor blockers increase the risk of myocardial infarction? Eur Heart J. 2005;26:2381-2386.

44. Volpe M, Mancia G, Trimarco B. Angiotensin II receptor blockers and myocardial infarction: deeds and misdeeds. J Hypertens. 2005;23: 2113-2118.

45. Epstein BJ, Gums JG. Angiotensin receptor blockers versus ACE inhibitors: prevention of death and myocardial infarction in high-risk populations. Ann Pharmacother. 2005;39:470-480.

46. Brown B, Hall AS. Renin-angiotensin system modulation: the weight of evidence. Am J Hypertens. 2005;18:127S-133S.

47. Turnbull F, Neal B, Pfeffer M, et al. Blood pressure-dependent and independent effects of agents that inhibit the renin-angiotensin system. J Hypertens. 2007;25:951-958.

48. Verma S, Mamdani MM, Al-Omran M, et al. ARBs vs ACEIs and acute coronary syndrome outcomes in elderly patients: a population-based cohort study (UMPIRE study results). J Am Soc Hypertens. 2007;1:286-294.

49. Yusuf S, Teo KK, et al. ONTARGET Investigators; Telmisartan, ramipril, or both in patients at high risk for vascular events. $N$ Engl $J$ Med. 2008;358:1547-1549.

50. Staessen JA, Wang JG, Thijs L. Cardiovascular prevention and blood pressure reduction: a quantitative overview updated until 1 March 2003. J Hypertens. 2003;21:1055-1076.

51. Ligtenberg G, Blankestijn PJ, Oey PL, et al. Reduction of sympathetic hyperactivity by enalapril in patients with chronic renal failure. $N E n g l$ J Med. 1999;340:1321-1328.

52. Turnbull F. Effects of different blood-pressure-lowering regimens on major cardiovascular events: results of prospectively-designed overviews of randomised trials. Lancet. 2003;362:1527-1535.

53. Turnbull F, Neal B, Algert C, et al. Effects of different blood pressurelowering regimens on major cardiovascular events in individuals with and without diabetes mellitus: results of prospectively designed overviews of randomized trials. Arch Intern Med. 2005;165:1410-1419.

54. Massie BM, Carson PE, McMurray JJ, et al. Irbesartan in patients with hearth failure and preserved ejection fraction. $N$ Engl $J$ Med. 2008;359:2456-2467.

55. Wachtell K, Lehto M, Gerdts E, et al. Angiotensin II receptor blockade reduces new-onset atrial fibrillation and subsequent stroke compared to atenolol: the Losartan Intervention For End Point Reduction in Hypertension (LIFE) study. J Am Coll Cardiol. 2005;45:712-719.

56. Madrid AH, Bueno MG, Rebollo JM, et al. Use of irbesartan to maintain sinus rhythm in patients with long-lasting persistent atrial fibrillation: a prospective and randomized study. Circulation. 2002;106:331-336. 
57. Galzerano D, Caselli S, Breglio R, et al. A multicentre, randomized study comparing efficacy of telmisartan versus carvedilol in preventing atrial fibrillaion recurrence in hypertensive patients. Circulation. 2007;116:556-557.

58. Yusuf S, Connolly S, on behalf of the ACTIVE Investigators. A randomized evaluation of irbesartan versus placebo in patients with Atrial Fibrillation (factorial design of ACTIVE Program). Oral presentation at the European Society of Cardiology Congress 2009, Aug 29-Sep 22009 , Barcelona, Spain. Available from: http://www.escardio.org/congresses/ esc-2009/congress-reports/pages/708005-708006-yusuf-brugada.aspx. Accessed October 292009.

59. Pedersen OD, Bagger H, Kober L, et al. Trandolapril reduces the incidence of atrial fibrillation after acute myocardial infarction in patients with left ventricular dysfunction. Circulation. 1999;100:376-380.

60. Vermes E, Tardif JC, Bourassa MG, et al. Enalapril decreases the incidence of atrial fibrillation in patients with left ventricular dysfunction: insight from the Studies Of Left Ventricular Dysfunction (SOLVD) trials. Circulation. 2003;107:2926-2931.

61. Everett TH, Li H, Mangrum JM, et al. Electrical, morphological, and ultrastructural remodeling and reverse remodeling in a canine model of chronic atrial fibrillation. Circulation. 2000;102:1454-1460.

62. Allessie MA. Atrial electrophysiologic remodeling: another vicious circle? J Cardiovasc Electrophysiol. 1998;9:1378-1393.

63. Nakashima H, Kumagai K, Urata H, et al. Angiotensin II antagonist prevents electrical remodeling in atrial fibrillation. Circulation. 2000;101:2612-2617.

64. Zhang H, Thijs L, Staessen JA. Blood pressure lowering for primary and secondary prevention of stroke. Hypertension. 2006;48:187-195.

65. Ohkubo T, Asayama K, Kikuya M, et al. Prediction of ischaemic and haemorrhagic stroke by self-measured blood pressure at home: the Ohasama study. Blood Press Monit. 2004;9:315-320.

66. Verdecchia P, Reboldi G, Angeli F, et al. Angiotensin-converting enzyme inhibitors and calcium channel blockers for coronary heart disease and stroke prevention. Hypertension. 2005;46:386-392.

67. Parving HH, Lehnert H, Bröchner-Mortensen J, et al. The effect of irbesartan on the development of diabetic nephropathy in patients with type 2 diabetes. N Engl J Med. 2001;345:870-878.

68. Rossing K, Christensen PK, Andersen S, et al. Comparative effects of irbesartan on ambulatory and office blood pressure: a substudy of ambulatory blood pressure from the Irbesartan in Patients with Type 2 Diabetes and Microalbuminuria study. Diabetes Care. 2003;26: 569-574.

69. Brenner BM, Cooper ME, de Zeeuw D, et al. Effects of losartan on renal and cardiovascular outcomes in patients with type 2 diabetes and nephropathy. N Engl J Med. 2001;345:861-869.

70. Lewis EJ, Hunsicker LG, Clarke WR, et al. Renoprotective effect of the angiotensin-receptor antagonist irbesartan in patients with nephropathy due to type 2 diabetes. N Engl J Med. 2001;345:851-860.

71. Barnett AH, Bain SC, Bouter P, et al. Angiotensin-receptor blockade versus converting-enzyme inhibition in type 2 diabetes and nephropathy. N Engl J Med. 2004;351:1952-1961.

72. Bakris G, Burgess E, Weir M, et al. Telmisartan is more effective than losartan in reducing proteinuria in patients with diabetic nephropathy Kidney Inti. 2008;74:364-369.

73. Yusuf S, Teo K, et al. TRANSCEND Investigators. Effects of the angiotensin-receptor blocker telmisartan on cardiovascular events in high-risk patients intolerant to angiotensin-converting enzyme inhibitors: a randomized controlled trial. Lancet. 2008;372:1174-1183.

74. Dagenais GR, Pogue J, Fox K, et al. Angiotensin-converting-enzyme inhibitors in stable vascular disease without left ventricular systolic dysfunction or heart failure: a combined analysis of three trials. Lancet. 2006;368:581-588.

75. Danchin N, Cucherat M, Thuillez C, et al. Angiotensin-converting enzyme inhibitors in patients with coronary artery disease and absence of heart failure or left ventricular systolic dysfunction: an overview of long-term randomized controlled trials. Arch Intern Med. 2006; 166:787-796.
76. Solomon SD, Janardhanan R, Verma A, et al. Effect of angiotensin receptor blockade and antihypertensive drugs on diastolic function in patients with hypertension and diastolic dysfunction: a randomised trial. Lancet. 2007;369:2079-2087.

77. Ahmed A, Perry GJ, Husain A. VALIDD should not invalidate angiotensin-receptor blockers. Lancet. 2007;369:2053-2054.

78. Ferrario CM. Role of angiotensin II in cardiovascular disease therapeutic implications of more than a century of research. J Renin Angiotensin Aldosterone Syst. 2006;7:3-14.

79. Doran DE, Weiss D, Zhang Y, et al. Differential effects of $\mathrm{AT}_{1}$ receptor and $\mathrm{Ca} 2+$ channel blockade on atherosclerosis, inflammatory gene expression, and production of reactive oxygen species. Atherosclerosis. 2007; 195:39-47.

80. Jung KH, Chu K, Lee ST, et al. Blockade of AT receptor reduces apoptosis, inflammation, and oxidative stress in normotensive rats with intracerebral hemorrhage. J Pharmacol Exp Ther. 2007;322:1051-1058.

81. Luchtefeld M, Bandlow N, Tietge UJ, et al. Angiotensin II type 1receptor antagonism prevents type IIA secretory phospholipase A2-dependent lipid peroxidation. Atherosclerosis. 2007;194:62-70.

82. Suzuki Y, Ruiz-Ortega M, Lorenzo O, et al. Inflammation and angiotensin II. Int J Biochem Cell Biol. 2003;35:881-900.

83. Linz W, Scholkens BA. A specific B2-bradykinin receptor antagonist HOE 140 abolishes the antihypertrophic effect of ramipril. $\mathrm{Br} J$ Pharmacol. 1992;105:771-772.

84. Okada H, Watanabe Y, Kikuta T, et al. Bradykinin decreases plasminogen activator inhibitor-1 expression and facilitates matrix degradation in the renal tubulointerstitium under angiotensin-converting enzyme blockade. J Am Soc Nephrol. 2004;15:2404-2413.

85. Scholkens BA, Linz W, Konig W. Effects of the angiotensin converting enzyme inhibitor, ramipril, in isolated ischaemic rat heart are abolished by a bradykinin antagonist. J Hypertens Suppl. 1988;6:S25-S28.

86. Smith D, Gilbert M, Owen WG. Tissue plasminogen activator release in vivo in response to vasoactive agents. Blood. 1985;66:835-839.

87. Stein JH, Congbalay RC, Karsh DL, et al. The effect of bradykinin on proximal tubular sodium reabsorption in the dog: evidence for functional nephron heterogeneity. J Clin Invest. 1972;51:1709-1721.

88. Unger T, Mattfeldt T, Lamberty V, et al. Effect of early onset angiotensin converting enzyme inhibition on myocardial capillaries. Hypertension. 1992;20:478-482.

89. Vanhoutte PM, Boulanger CM, Mombouli JV. Endothelium-derived relaxing factors and converting enzyme inhibition. Am J Cardiol. 1995;76:3E-12E.

90. Dykewicz MS. Cough and angioedema from angiotensin-converting enzyme inhibitors: new insights into mechanisms and management. Curr Opin Allergy Clin Immunol. 2004;4:267-270.

91. Jorde UP, Ennezat PV, Lisker J, et al. Maximally recommended doses of angiotensin-converting enzyme (ACE) inhibitors do not completely prevent ACE-mediated formation of angiotensin II in chronic heart failure. Circulation. 2000;101:844-846.

92. Roig E, Perez-Villa F, Morales M, et al. Clinical implications of increased plasma angiotensin II despite ACE inhibitor therapy in patients with congestive heart failure. Eur Heart J. 2000;21:53-57.

93. Doulton TW, He FJ, MacGregor GA. Systematic review of combined angiotensin-converting enzyme inhibition and angiotensin receptor blockade in hypertension. Hypertension. 2005;45:880-886.

94. Kasama S, Toyama T, Kumakura H, et al. Addition of valsartan to an angiotensin-converting enzyme inhibitor improves cardiac sympathetic nerve activity and left ventricular function in patients with congestive heart failure. J Nucl Med. 2003;44:884-890.

95. Suzuki H, Kanno Y, Kaneko K, et al. Comparison of the effects of angiotensin receptor antagonist, angiotensin converting enzyme inhibitor, and their combination on regression of left ventricular hypertrophy of diabetes type 2 patients on recent onset hemodialysis therapy. Ther Apher Dial. 2004;8:320-327.

96. Petrovic J, Petrovic D, Vukovic N, et al. Ventricular and vascular remodelling - effects of the angiotensin II receptor blocker telmisartan and/or the angiotensin-converting enzyme inhibitor ramipril in hypertensive patients. J Int Med Res. 2005;33(Suppl 1):39A-49A. 
97. Cohn JN, Tognoni G; for the Valsartan Heart Failure Trial Investigators. A randomized trial of the angiotensin-receptor blocker valsartan in chronic heart failure. $N$ Engl J Med. 2001;345:1667-1675.

98. McMurray JJ, Ostergren J, Swedberg K, et al. Effects of candesartan in patients with chronic heart failure and reduced left-ventricular systolic function taking angiotensin-converting-enzyme inhibitors: the CHARM-Added trial. Lancet. 2003;362:767-771.

99. Mancia G, Laurent S, Agabiti-Rosei E, et al. Reappraisal of European guidelines on hypertension management: a European Society of Hypertension Task Force document. J Hypertens. 2009;27:2121-2158.

100. Dahlöf B, Sever PS, Poulter NR, et al. Prevention of cardiovascular events with an antihypertensive regimen of amlodipine adding perindopril as required versus atenolol adding bendroflumethiazide as required, in the Anglo-Scandinavian Cardiac Outcomes Trial-Blood Pressure Lowering Arm (ASCOT-BPLA): a multicentre randomised controlled trial. Lancet. 2005;366:895-906.
101. Young JB, Dunlap ME, Pfeffer MA, et al. Mortality and morbidity reduction with Candesartan in patients with chronic heart failure and left ventricular systolic dysfunction: results of the CHARM low-left ventricular ejection fraction trials. Circulation. 2004;110: 2618-2626.

102. Pfeffer MA, Swedberg K, Granger CB, et al. Effects of candesartan on mortality and morbidity in patients with chronic heart failure: the CHARM-Overall programme. Lancet. 2003;362:759-766.

103. Braunwald E, Domanski MJ, Fowler SE, et al; the PEACE Trial Investigators. Angiotensin-converting-enzyme inhibition in stable coronary artery disease. $N$ Engl J Med. 2004;351:2058-2068.
Vascular Health and Risk Management

\section{Publish your work in this journal}

Vascular Health and Risk Management is an international, peerreviewed journal of therapeutics and risk management, focusing on concise rapid reporting of clinical studies on the processes involved in the maintenance of vascular health; the monitoring, prevention and treatment of vascular disease and its sequelae; and the involvement of

\section{Dovepress}

metabolic disorders, particularly diabetes. This journal is indexed on PubMed Central and MedLine. The manuscript management system is completely online and includes a very quick and fair peer-review system, which is all easy to use. Visit http://www.dovepress.com/ testimonials.php to read real quotes from published authors. 